\title{
MODELLING OF FUZZY LOGIC CONTROLLER FOR VARIABLE- STEP MPPT IN PHOTOVOLTAIC SYSTEM
}

\author{
C. P. Roy ${ }^{1}$, D. Vijaybhaskar ${ }^{2}$, T.Maity ${ }^{3}$ \\ ${ }^{1,2,3}$ Department of Electrical Engineering, \\ Indian School of Mines, Dhanbad, Jharkhand, India \\ prakashroy2507@gmail.com,devaravijay@gmail.com
}

\begin{abstract}
The output power of photovoltaic electrical systems is highly dynamic and non-linear in nature. In order to extract maximum power from such systems, maximum power point tracking (MPPT) technique is required. MPPT techniques with variable step-size of perturbation track the maximum power point (MPP) with more efficiency. In this paper, a model of a fuzzy logic controller (FLC) for determining the step-size of perturbation in duty-cycle of a photovoltaic electrical system to track MPP is presented. The model is simulated in MATLAB/Simulink ${ }^{\circledR}$.
\end{abstract}

Keywords: Maximum power point tracking, perturb and observe, boost converter, fuzzy logic control, membership function, crisp universe, centre of area, pulse width modulation.

\section{INTRODUCTION}

Photovoltaic electrical systems are those which convert the energy of photons directly into electrical energy. The output power of such a system is highly sensitive to the environmental parameters like- insolation and temperature. Hence, the maximum power that can be extracted from a panel also changes with change in these parameters. In order to ensure maximum extraction of power from a PV panel under varying environmental conditions load should be changed in accordance with changing environmental parameters, so that the operating point or quiescent point always lies at the maximum power point. Since, practically it is not possible to change the load time to time; there must be some interfacing circuit in between the PV panel and the load which can change the load (as seen from the side of $\mathrm{PV}$ terminals, i.e. between terminals $E \& F$ ) with change in environmental parameters depending upon some control variables. As the output of PV panel is of DC in nature, generally switched mode power converters (DC to DC converters) are used as the interfacing circuit. Fig.1 shows the block diagram of photovoltaic electrical system.

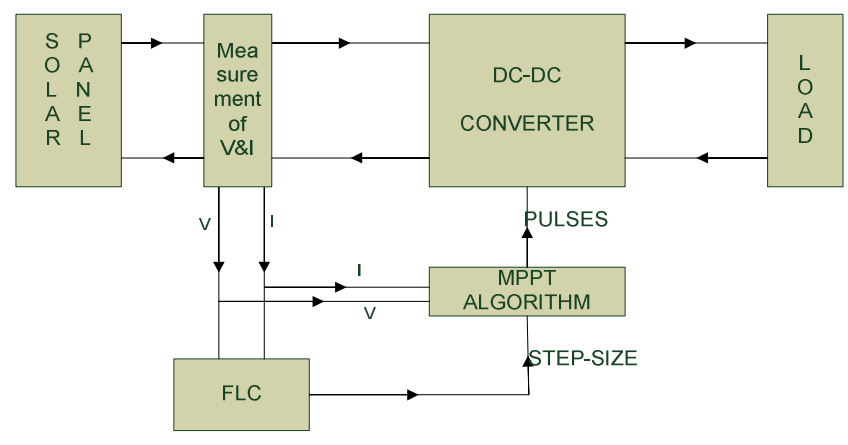

Fig.1 Block diagram of photovoltaic electrical system

The operating point is changed by varying the duty-cycle of these power converters [1]. There are so many techniques in literature according to which the duty-cycle of these converters can be changed to track the maximum power point. In this paper, variable-step perturb and observe algorithm has been used for this purpose [2]. Variable step-size of perturbation ensures time efficient tracking and at the same time gives better stability in output power at maximum power point. In order to determine smooth and quick variation in step-size, fuzzy logic control has been used in this paper.

The paper is organised as such: in section 2 photovoltaic electrical system model is presented; maximum power point algorithm and modelling of fuzzy logic controller is presented in section 3. Results and discussions are made in section 4 and finally conclusions are drawn in section 5 . 


\section{MODELLING OF PHOTOVOLTAIC}

\section{ELECTRICAL SYSTEM}

\subsection{SOLAR PANEL}

For analysis purpose, single diode model of solar panel is considered in this paper as shown in Fig.2.

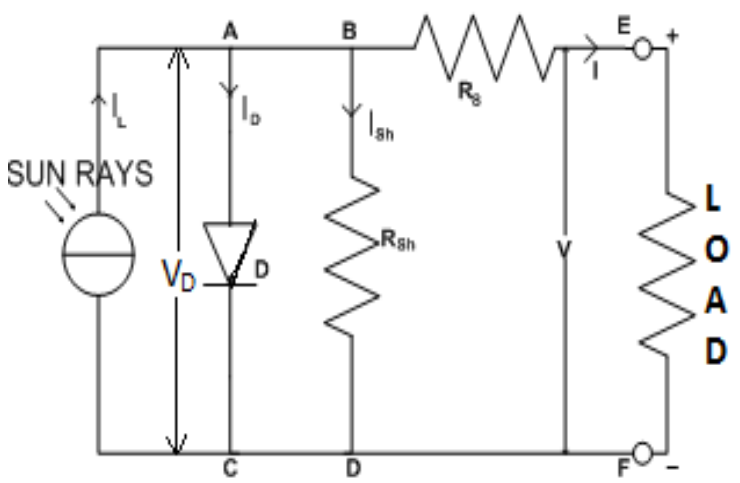

Fig.2 single diode model of solar cell.

The same model is built in MATLAB/Simulink ${ }^{\circledR}$ as shown in Fig.3. The effect of temperature and irradiance on photogenerated current ILis estimated using (1) and (2) [3]. All the parameter values are tabulated in Table-1.

$I_{L}=I_{L}\left(T_{r}\right)\left(1+K_{i}\left(T-T_{r}\right)\right.$

$I_{L}\left(T_{r}\right)=I_{s c}\left(\frac{G}{G_{0}}\right)$

Where, ILis photo-generated current (A), $\mathrm{T}$ is absolute climatic temperature $(\mathrm{K}), \mathrm{Ki}$ is short-circuit current temperature coefficient $(\mathrm{A} / \mathrm{K}), \mathrm{G}$ is insolation $(\mathrm{W} / \mathrm{m} 2)$, GO\&TO are standard insolation and temperature respectively.

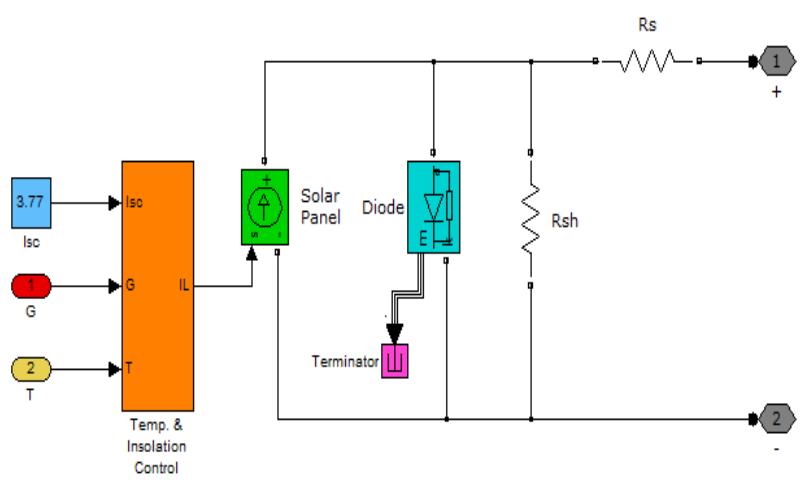

Fig.3 Simulink model of solar panel.
Table-1 Parametric details of solar panel.

\begin{tabular}{|l|l|}
\hline Parameters & Values \\
\hline Vmax & $17 \mathrm{~V}$ \\
\hline Imax & $3.5 \mathrm{~A}$ \\
\hline Pmax & $60 \mathrm{~W}$ \\
\hline VOC & $21 \mathrm{~V}$ \\
\hline ISC & $3.7 \mathrm{~A}$ \\
\hline Encapsulated solar cell efficiency & $15 \%$ \\
\hline Module efficiency & $12.1 \%$ \\
\hline Size of Panel & $93.75 \times 125 \mathrm{~mm} 2$ \\
\hline Cell type & Mono Crystalline \\
\hline NP & 1 \\
\hline NS & 36 \\
\hline Ki & $1.7 \times 103 \mathrm{~A} / \mathrm{K}$ \\
\hline RS (of a single cell) & $0.03 \Omega$ \\
\hline RSh(of a single cell) & $10000 \Omega$ \\
\hline STC(Standard Test Condition) & $\mathrm{K}, 1000 \mathrm{~W} / \mathrm{m} 2$ \\
\hline
\end{tabular}

\subsection{POWER ELECTRONICS COMPONENTS}

With change in temperature and irradiance, internal resistance of solar panel also changes. The change in characteristics of I-V and P-V curves of a solar panel with varying irradiance and temperature is shown in Fig4. From the curves obtained, it can be inferred that with increase in irradiance level, net output power increases while with increase in ambient temperature, it decreases non-linearly.

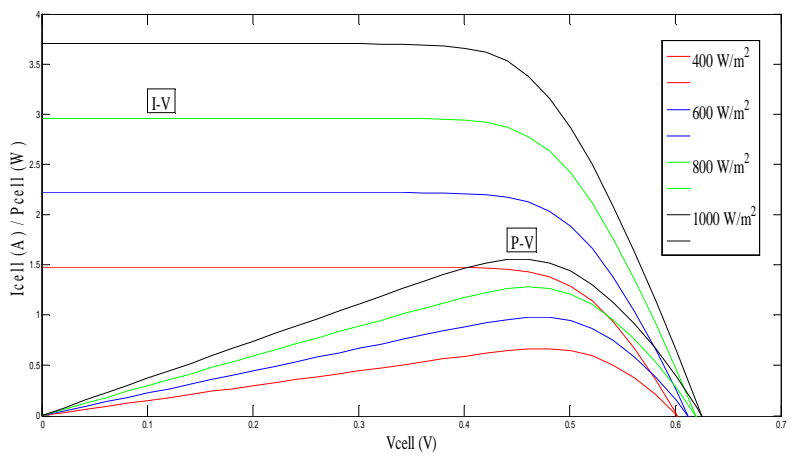

(a) 


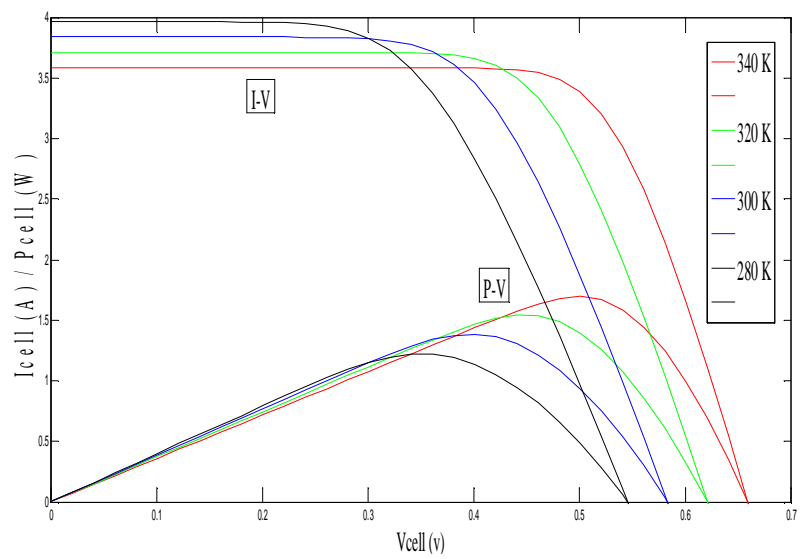

(b)

Fig.4 Variation in PV output characteristics with changing (a) insolation (b) temperature.

To extract maximum output power, the output resistance as seen from the panel side must be equal to its internal resistance. Therefore, the interfacing circuit must have an efficient impedance matching property. Switched mode power regulators [4] help to incorporate this property in photovoltaic systems. By varying the duty-cycle of switching element used in the topology, it is possible to change the resistance as seen from the input terminals of these regulators as shown in Fig.5[1].

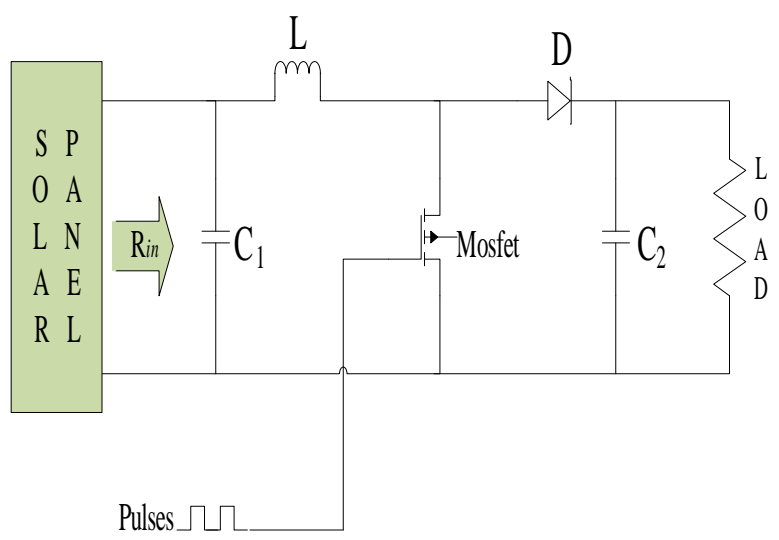

Fig.5 Topology of boost converter.

In this paper boost converter [5] is used as the interfacing circuit as shown in Fig.4. The capacitor $\mathrm{C} 1$ has been used to reduce the fluctuation in voltage at input terminals of the boost converter. The parametric details of the modelled boost converter have been provided in Table- 2 . RL is the equivalent series resistance (ESR) of inductor; $\mathrm{RC} 1$ and $\mathrm{RC} 2$ are the ESR of the capacitors $\mathrm{C} 1$ and $\mathrm{C} 2$ respectively.
Table-2 Parametric details of boost converter.

\begin{tabular}{|l|l|}
\hline Parameters & Values \\
\hline Rc1 & $11.23 \mathrm{~m} \Omega$ \\
\hline C1 & $76.8 \mathrm{mF}$ \\
\hline Rc2 & $9.44 \mathrm{~m} \Omega$ \\
\hline $\mathrm{C} 2$ & $74.8 \mathrm{mF}$ \\
\hline RL & $18.92 \mathrm{~m} \Omega$ \\
\hline L & $4.2912 \mathrm{mH}$ \\
\hline Diode threshold voltage & $0.7 \mathrm{~V}$ \\
\hline Diode ON resistance & $190 \mu \Omega$ \\
\hline MOSFET ON resistance & $20 \mathrm{~m} \Omega$ \\
\hline Switching frequency & $5 \mathrm{kHz}$ \\
\hline
\end{tabular}

Under steady state, the relation between input and output resistances of a boost converter is governed using (3) [6].

$$
R_{\text {in }}=(1-d)^{2} R_{L O A D}
$$

Where, Rin is the input resistance and RLOAD is the output load resistance. From (3), it's quite clear that by varying the duty-cycle $d$, the input resistance can easily be changed.

\section{MAXIMUM POWER POINT TRACKING 3.1 PERTURB AND OBSERVE ALGORITHM}

The switched mode power regulators change the output resistance of solar panel depending upon the change in its dutycycle. But, the manner in which the duty-cycle should be varied is decided by some artificial intelligence techniques called as maximum power point tracking (MPPT). In this paper, perturb and observe $(\mathrm{P} \& \mathrm{O})$ technique [2] with variable step-size of perturbation has been used for tracking the maximum power point (MPP). The complete working of $\mathrm{P} \& \mathrm{O}$ algorithm is shown as flowchart in Fig.6. The step-size of perturbation is varied proportional to the distance of quiescent point (i.e. present operating point) from the MPP using a fuzzy logic controller. As the quiescent point approaches the MPP, the step-size is gradually reduced to zero. 


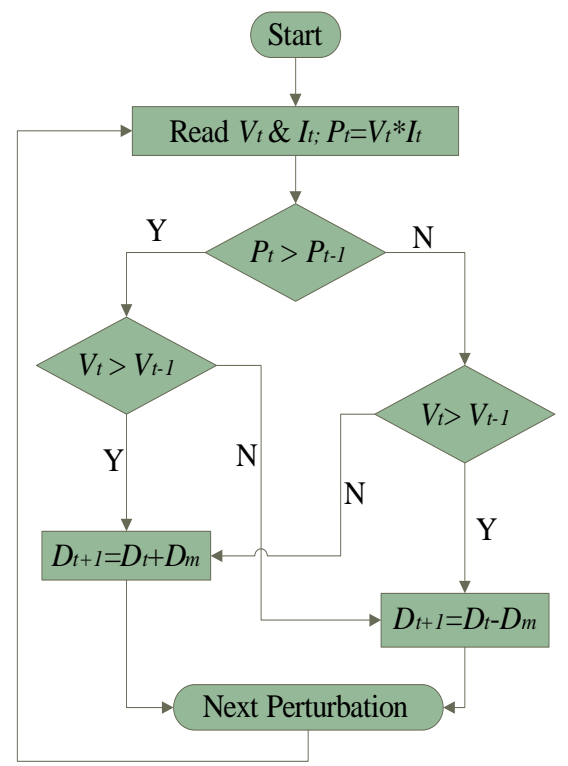

Fig.6 P\&O algorithm.

In the flowchart given in Fig.5,t represents the iteration, $\mathrm{t}-1$ represents the previous iteration and $t+1$ represents the next future iteration. $\mathrm{D}$ is the constant signal which is being compared with a ramp signal to produce square pulses of desired duty-cycle and Dm is the step-size of perturbation as determined by the fuzzy logic controller.

\subsection{MODELLING OF FUZZY LOGIC CONTROLLER}

The complete working of Fuzzy Logic Controller is categorised into three different domains as discussed under [7, 8]:

\subsubsection{FUZZIFICATION}

Fuzzification is the process of representation of different crisp variables by the predefined fuzzy subsets. In this paper, slope of the P-V curve, slope and the perturbation of previous step i.e. $\Delta \mathrm{D}$ are chosen as crisp variables and the crisp universe is partitioned into five different fuzzy subsets giving rise to total twenty-five subsets in fuzzy output universe. For partition of crisp universe, triangular membership function has been used as shown in (4) [9].

$\mu(x)=\max \left[\min \left\{\frac{x-x_{1}}{x_{2}-x_{1}}, \frac{x_{3}-x}{x_{3}-x_{2}}\right\}, 0\right]$

Where, $\mathrm{x}$ is the crisp variable and $\mathrm{x} 1, \mathrm{x} 2 \& \mathrm{x} 3$ are critical crisp points corresponding to left end, peak value $\&$ right end of the crisp universe.
The modelling of membership function and the fuzzifier in MATLAB/Simulink ${ }^{\circledR}$ are shown in Fig.7 (a) and Fig.7 (b) respectively.

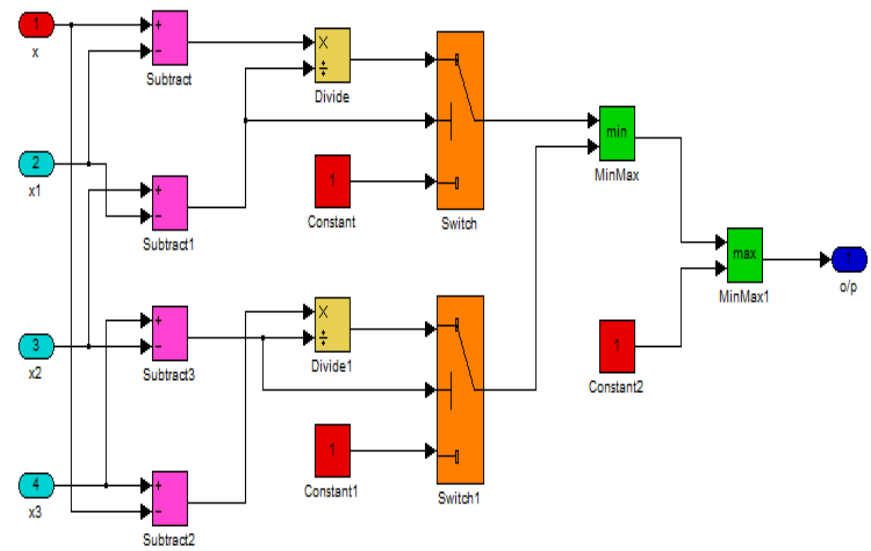

(a)

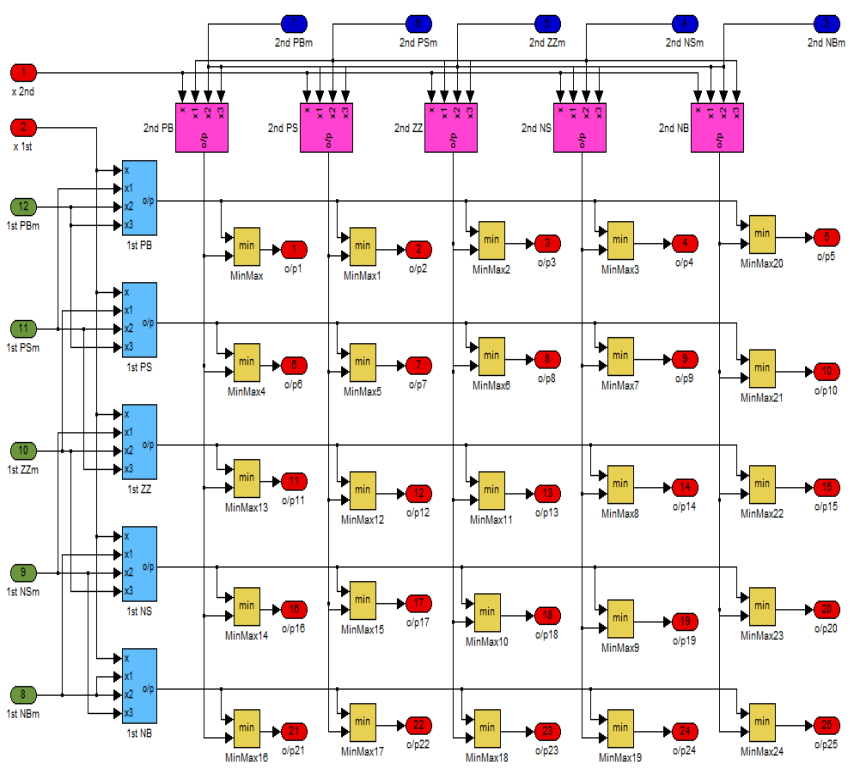

(b)

Fig.7 Simulink model of (a) membership function (b) crisp universe partition.

\subsubsection{FUZZY RULES}

Fuzzy Rules refer to a set of pre-defined instructions which link the different values of crisp variables with different subsets of fuzzy output space. The fuzzy based rules used in this paper are shown in Table- 3 and its MATLAB/Simulink $®$ implementation is presented in Fig.8. These rules are framed based on the logic that if the quiescent point is far away from MPP, then step-size of perturbation should be very large and it should be gradually decreased to zero as the operating point approaches to zero. At MPP, the slope of P-V curve will be zero; hence the 
perturbation should also become zero so that stability in the power can be achieved

Table-3 Fuzzy based rules.

\begin{tabular}{|c|c|c|c|c|c|c|c|}
\hline \multicolumn{8}{|c|}{$\mathrm{X}$ 2nd } \\
\hline \multirow{7}{*}{$\begin{array}{l}X \\
1 \\
S \\
t\end{array}$} & \multicolumn{2}{|c|}{ SLOPE } & PB & PS & $\mathrm{ZZ}$ & NS & NB \\
\hline & $\mathrm{dD}$ & & 5.0 & 0.1 & 0.0 & -0.1 & -5.0 \\
\hline & PB & 0.10 & $\mathrm{ZZ}$ & PS & $\overline{Z Z}$ & PS & PB \\
\hline & PS & 0.01 & PB & $\mathrm{ZZ}$ & $\mathrm{ZZ}$ & PS & PB \\
\hline & $\mathrm{ZZ}$ & 0.00 & PB & PS & $\mathrm{ZZ}$ & PS & PB \\
\hline & PS & 0.01 & $\mathrm{~PB}$ & PS & $\mathrm{ZZ}$ & $\mathrm{ZZ}$ & $\mathrm{PB}$ \\
\hline & PB & 0.10 & PB & PS & $\mathrm{ZZ}$ & PS & $\mathrm{ZZ}$ \\
\hline
\end{tabular}

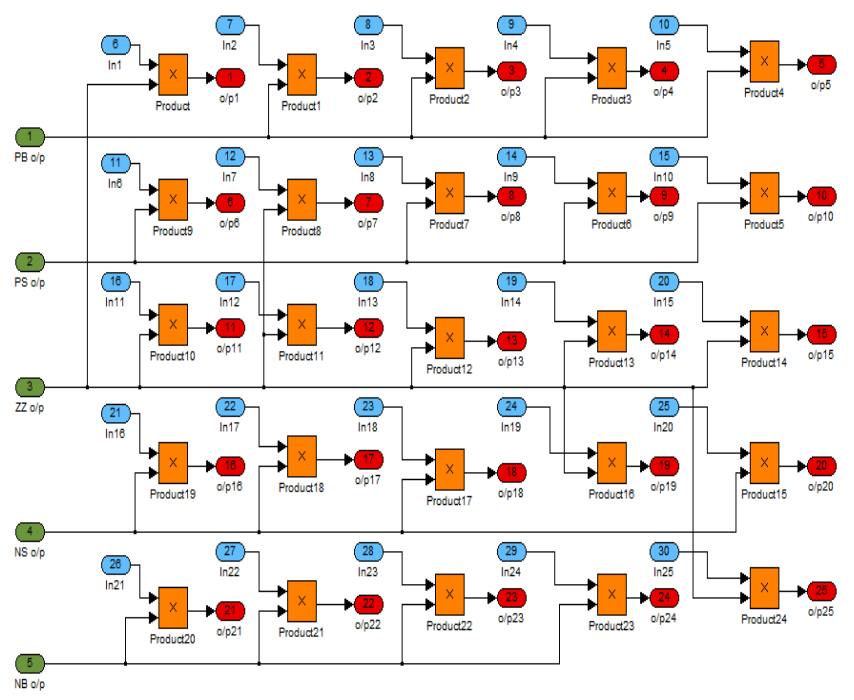

Fig.8 Simulink model for fuzzy rules.

\subsubsection{DEFUZZIFICATION}

Defuzzification is the method of finding final crisp value in fuzzy output space. The values of membership functions determine the weightage of different subsets in fuzzy output universe. To obtain the final crisp output, the centre of area[10] method on the weightages of these different fuzzy subsets (of output universe) has been used in this paper. The MATLAB/Simulink® implementation of defuzzification process is shown in Fig.9.

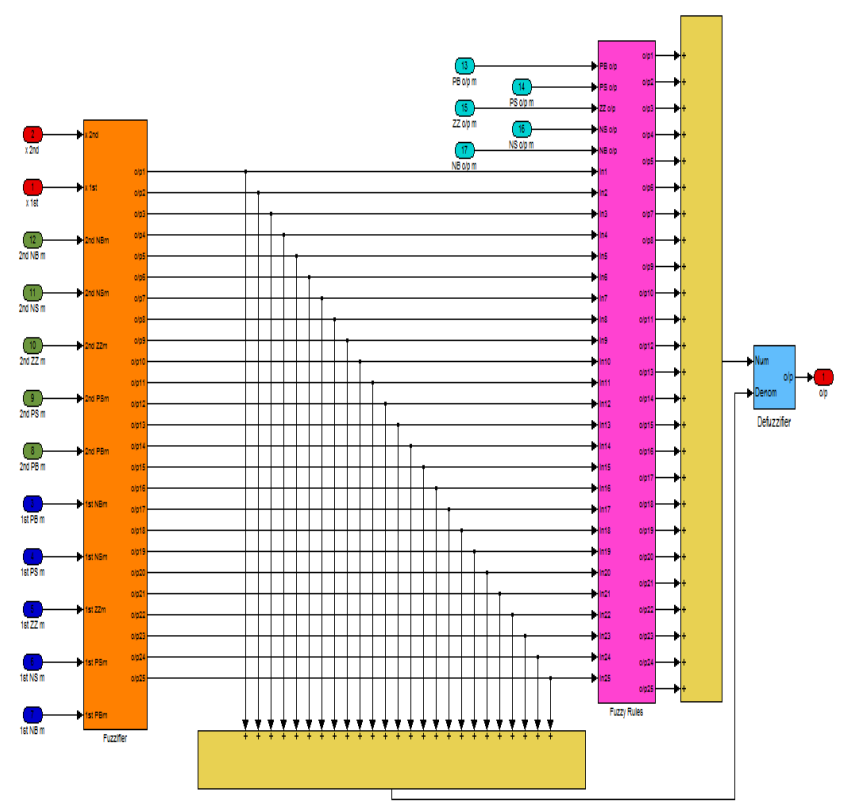

Fig.9 Model for defuzzification.

The final overall MATLAB/Simulink ${ }^{\circledR}$ model of MPPT using FLC for variable step-size estimation is shown in Fig.10. The critical crisp values for the two inputs $\mathrm{X} 1$ st (i.e. $\Delta \mathrm{D}$, step-size of previous perturbation) and $X$ 2nd (i.e. slope) and the output (i.e. $\mathrm{dD}$ ) have been fixed as per the choice and requirement after iterative simulations of the model. The crisp values are same as provided in Table- 3 . 


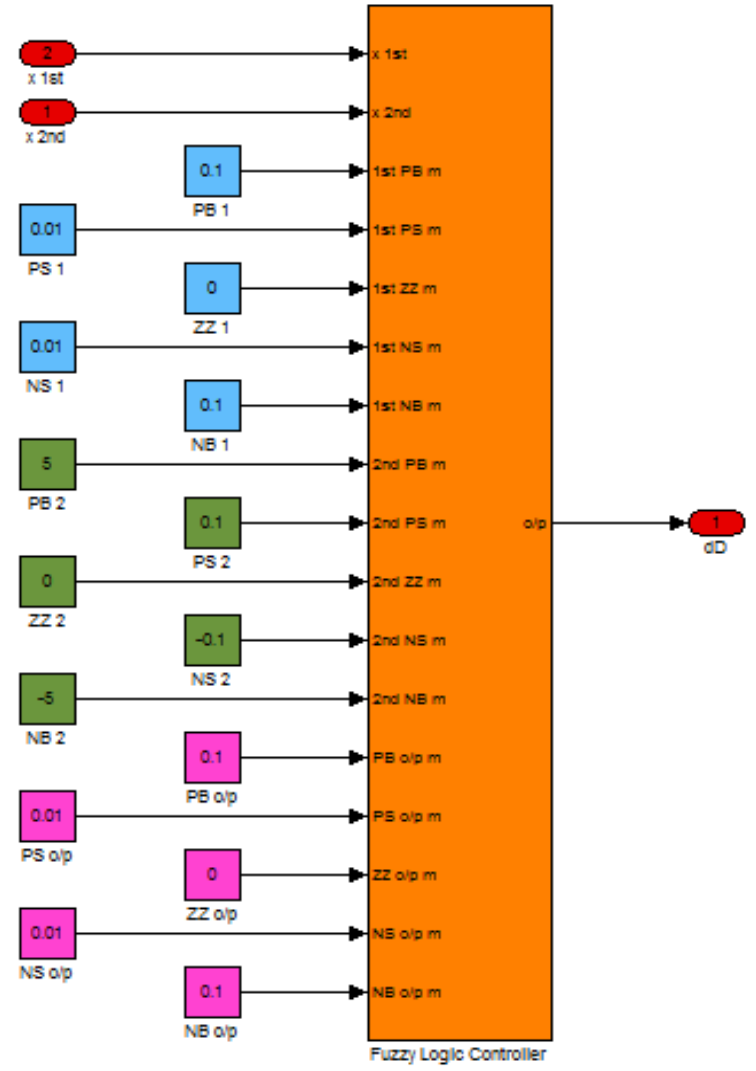

(a)

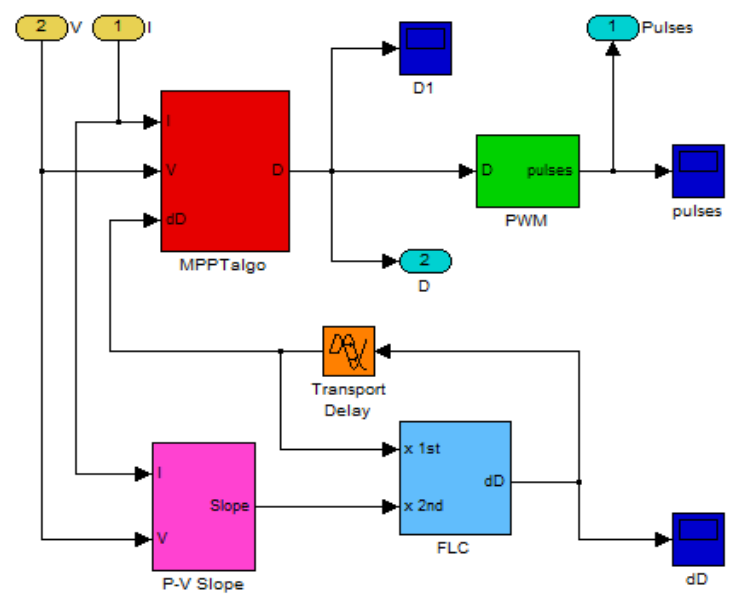

(b)

Fig.10 Complete Simulink model of (a) fuzzy logic controller, (b) MPPT algorithm using FLC

The panel output current and voltage are fed as input to both the $\mathrm{P} \& \mathrm{O}$ algorithm (for determining the direction of perturbation) and FL based controller (for determining the stepsize of perturbation). The ultimate value of $\mathrm{D}$ as obtained from this block is used to generate pulses for switching device of boost converter. For switching pulse generation, ramp PWM technique has been used.

\section{RESULTS AND DISCUSSIONS}

The Simulink model of the PV system is shown in Fig.11, it was simulated in MATLABfor a resistive load of $30 \mathrm{ohm}$ to judge the performance of variable-step MPPT for PV system under changing insolation condition.

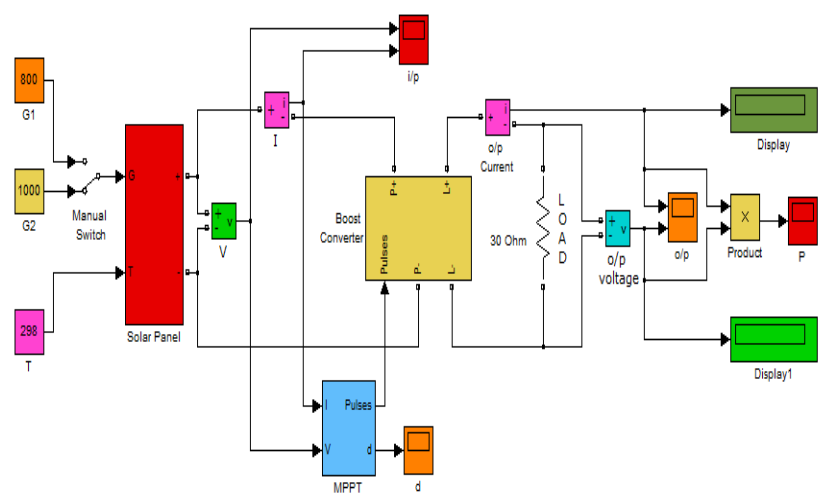

Fig.11 Simulink model of overall PV system

The tracking of MPP is presented on power(W) vs time(s) curve as obtained from simulation in Fig.12. The simulation was started at $\mathrm{t}=0$; and after reaching the MPP at $900 \mathrm{~W} / \mathrm{m} 2$, the irradiance was changed to $1000 \mathrm{~W} / \mathrm{m} 2$ using a manual switch as shown in Fig.11. The complete model as shown in Fig.10 is represented by a single block in Fig.11. From the result shown in Fig.12 it's quite clear that the system works efficiently in tracking the MPP under varyingenvironmental condition. Here, it has been tested for change in irradiance level.

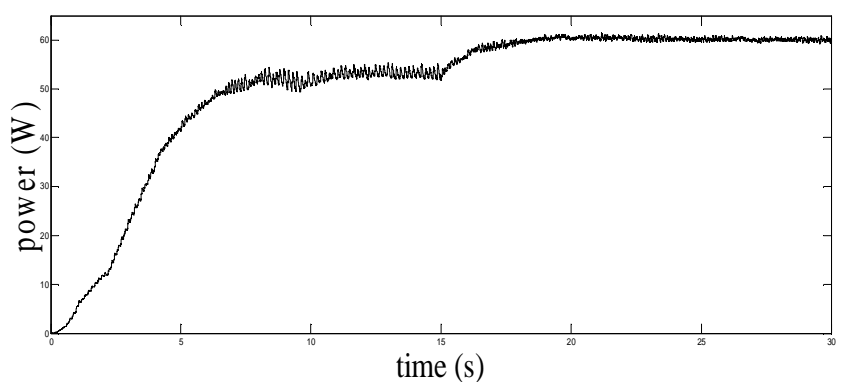

Fig.12 MPP tracking using FLC based variable-step P\&O algorithm

\section{CONCLUSIONS}

In this paper, a fuzzy logic controller is modelled in MATLAB/SIMULINK $®$ platform for determining the step-size of perturbation of variable step-size $\mathrm{P} \& \mathrm{O}$ algorithm for maximum power point tracking of a photovoltaic electrical 
system. The result shows that when the irradiance level is increased from $900 \mathrm{~W} / \mathrm{m} 2$ to $1000 \mathrm{~W} / \mathrm{m} 2$, the algorithm directs the operating point towards MPP to extract maximum power.

\section{REFERENCES}

[1] C.H and C.S , "Control of DC/DC converters for solar energy system with maximum power tracking", IECON 97. 23rd, 1997, vol. 2, pp. 827-832.

[2] W. T. Chee, T. C. Green, and A. H.-A. Carlos, "Analysis of perturb and observe maximum power point tracking algorithm for photovoltaic applications", IEEE 2nd Int. Pow. and Energy Conf., Johor Bahru, Malaysia, 2008.

[3] Mohsen Taherbaneh, Mohammad B.Menhaj, "A fuzzybased maximum power point tracker for body mounted solar panels in LEO satellites", In Proc: IEEE Ind \& Comm Pow. Syst Tech., May 2007, pp. 1-6.

[4] Solodovnik E.V., Shengyi Liu, Dougal R.A., " Power controller design for maximum power tracking in solar installations", J Trans Power Electron, 2004, Vol. 19(5), pp. 1295-1304.

[5] H. S. Kim, J. M. Park, K. B. Jo, H. W. L, “A Study on the Boost Converter for MPPT Using Micro-controller in PV System ", KSES CNF, 2003, pp. 51-60.

[6] H. Chung, Y. K. Mok, "Development of a switchedcapacitor dc-dc boost converter with continuous input current waveform", IEEE Trans. Circuits Syst. I, Fundam. Theory Appl., Jun. 1999, vol. 46(6), pp. 756-759.

[7] Won C.-Y., Kim D.-H., Kim S.-C., Kim W.-S., Kim H.-S., "A new maximum power point tracker of photovoltaic arrays using fuzzy controller". In Proc: 25th Annual IEEE PESC, 2025 Jun. 1994, vol. 1, pp. 396-403.

[8] Simoes M.G., Franceschettin N.N.: 'Fuzzy optimization based control of a solar array', In Proc. IEE Electr. Power Appl., 1999, 146, (5), pp. 552-558.

[9] Sung-Jun Kang, Jae-Sub Ko, Jung-Sik Choi, Mi-Geum Jang, Ju-Hui Mun, Jin-Gook Lee, Dong-Hwa Chung, "A Novel MPPT Control of photovoltaic system using FLC algorithm", 11th Int. Conf. on Cont. Auto. and Syst., Oct. 26-29, 2011, pp. 434-439.

[10] K. Passino and S. Yurkovich, "Fuzzy control", Reading, MA, USA: Addison-Wesley, 1998. 